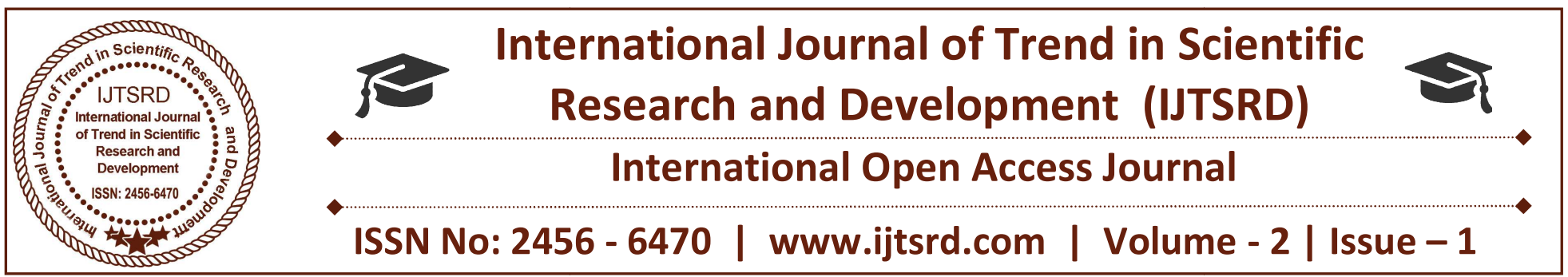

\title{
Applications of Nanobiotechnology in Food Packaging
}

\author{
Anjali Tripathi \\ Student, Shri Ramswaroop Memorial \\ University, Dewa Road, Lucknow, U.P.
}

\author{
Noopur Khare \\ Assistant Professor, Shri Ramswaroop Memorial \\ University, Dewa Road, Lucknow, U.P.
}

\begin{abstract}
In present scenario as world is moving at alarming rate in the same way technologies are also developing at alarming rate. Today, nanotechnology has given a very good application for packing material on molecular scale so as to give desired properties to the material. Simple packaging to food is being replaced by advanced packing by the help of nanotechnology. With the help of nanoparticles, bottles and packages with light resistance can be produced. These properties of packing increases the shelf life of food with preserving flavours and colors. The nanostructured film can also prevent the food from encountering of organisms like bacteria to ensure food safety. Nanosensors can be used in packaging purpose which can alarm us when food gets spoiled.
\end{abstract}

Keywords: Intelligent packaging, smart packaging, RFID (radiofrequency identifications tags), biosensors, active packaging, time-temperature indicators, gas indicators

\section{Introduction}

"Nanotechnology refers to a part of science and technology which tells about the control of matter on the atomic and molecular scale which means things that are about 1 to 100 nanometers". The start of nanotechnology comes from the ideas which were first used in talk - "there's plenty of room at bottom", a talk given by an American Physicist Richard Feynman at Caltech on Dec 29, 1959.

Food packaging refers to packaging used for foods which provide protection, tempering resistance and special physical, chemical or biological needs. It consists of nutrition facts, label and some other information about food which are being offered for sale[8].

Nanotechnology, an emerging platform for the development and transformation of agrifood production and packaging systems. In a present scenario movement of nanotechnology from laboratory and onto farm, supermarket, shelves and kitchen table (for ex smart agricultural inputs like nanoseed varieties, nanoencapsulation technique, to alter nutritional composition, flavor and other attributes. Production of nanoparticles includes breakdown of large amount of chemical compounds into nanoparticles. For the production of cheaper, more durable or greater quantities of existing products the techniques used are nanoparticles, nanodecider and other nano systems [1,2].Nanotechnology simply means involvement of nanotechnology for the manipulation or interchanging living organisms and enable the merging of biological as well as nanobiological materials for facilitating genetic engineered breeding programmes. Incorporation of synthetic materials into biological organisms and creating new forms of living systems [2]. Nanotechnology Research and Development facilitated and frame the next stage development of groups that are genetically modified crops, chemical pesticides, farming techniques in the Agriculture sector [3].

For delivering DNA and chemicals into plants and animal cells and tissues, silica nanoparticles have been used [3]. Nanosensors or nanoscale wireless sensors refers to the division of nanotechnologies and information technologies. With the large scale development of artificial nanocompounds in factories 
nanotechnology has displaced the traditional and non food form commodities. Nanotechnology is used in the production of processed foods and drinks, a variety of foods which contains nanocapsules which are available in present time for purchase and no indication of presence of nanomaterial's on food packaging. In the present day scenario, nano food packaging experiment the large scale development in the community. For improving the food quality, shelf life of the packaged food and its quality, manufacturers are using nanotechniques so that they can deliver the pathogen free food, and for this smart packaging has undermine the knowledge and skills of individuals in determining the freshness, purity and safety of foods. This smart packaging is engineered to warn the consumers that food is recognizing to spoilage or it is contaminated by some pathogen with the change in color of food $[5,7]$.

Reasons for using nanobiotechnology in food packaging are as follows:-

contamination sensor,

antimicrobial packaging,

improved food storage,

green packaging,

reduction of pesticides,

texture and flavor enhancer

tracing and tracking [7].

An emerging technology that uses communication function of packaging is the_intelligent packaging to enhance the quality of food and its safety. A proposed model of packaging functions is the intelligent packaging. Several types of packaging are divided into primary, secondary and tertiary:

\section{Primary}

1. Aseptic processing - liquid whole eggs or dairy products

2. Trays - portion of fish or meat

3. Bags - potato chips, apples, rice

4. Cans - can of tomato soup

5. Cartons - cartons of eggs, milk, juice

6. Flexible packaging - bagged salad

\section{Secondary}

Boxes - corrugated box of primary packages: box of cereal cartons, frozen pizzas

\section{Tertiary}

Pallets - transportation of a series of boxes on a single pallet to the distribution center from manufacturing plant.

1. Wrappers - used to wrap the boxes on the pallet for transport

Intelligent packaging has several functions a it monitors the condition and environment around the packaged foods. SENSORS -technology which respond against the change in the environment and contamination of foods. There several types of sensors spoilage which are using nano particles [6].

1. Oxygen sensors: $\mathrm{TiO}_{2},\left(\mathrm{NP}_{3}\right)$ in polymer which has blue dye that gives blue color in wich the exposure of $\mathrm{O}_{2}$

2. Gases sensors: conducts polymer nano composites/ electronic tongue which resistance the change of sensors which produces pattern of respective gases.

3. Electrochemical nanosensors: detects the presence of ethylene.

4. Time- temperature sensors: it confirms about processed food that have kept at the appropriate temperature dye migrates through nanoporous silica.

5. Ripeness sensors: gets reacted with certain aromas that are released by fruits as it ripens.

A system in which product, the package and environment interact in a positive way to extend shelf life is the Active packaging While maintaining the quality of food, the packaging system has changes the conditions to extend shelf life, food safety and sensory properties of packaging.A group of technology that uses packaging films to absorb gases(like $\mathrm{O}_{2}$, water vapours, ethylene from package headspace or to emit gases( such as $\mathrm{CO}_{2}, \mathrm{CH}_{3} \mathrm{CH}_{2} \mathrm{OH}$ )so that internal package environment and shelf life extensions which is favourable to the packaging is achieved is the_Gas emitting/ absorbing packaging. A group of technology that uses packaging materials to release active comounds( antimicrobials, enzymes, flavors) to protect against microbial spoilage and to enhance the food quality is the Controlled release packaging. Most attention in this group has been found on antimicrobial packaging. To control the permeation of oxygen, water vapour, and $\mathrm{CO}_{2}$ uses the breathable films that are known to be a selective permeable films. To the early development of food distribution system, traditional packaging contributed greater but 
now, but it is no longer sufficient because today's society has become very complex and so their food needs also [4,8]. Now, the food packaging has become innovative because consumer demands for minimally processed foods with fewer preservatives, food tourism, market globalization and concern about the food safety. In recent years, with the increase in frequency in conferences, symposium/journals and magazines, the term intelligent packaging has began to appear. Rijik, 2002 defined intelligent packaging as one that monitored the conditions of packaged foods to give information about the quality of food packaging and its storage. According to our definition, a packaging is 'smart', if it will be able to track the product

, scan the environmental conditions present inside or outside the package (For ex- Smart packaging is one that monitor the quality of food and its safety conditions, its gradients like flavor and mixtures, manufacturing conditions, environments etc) [9].

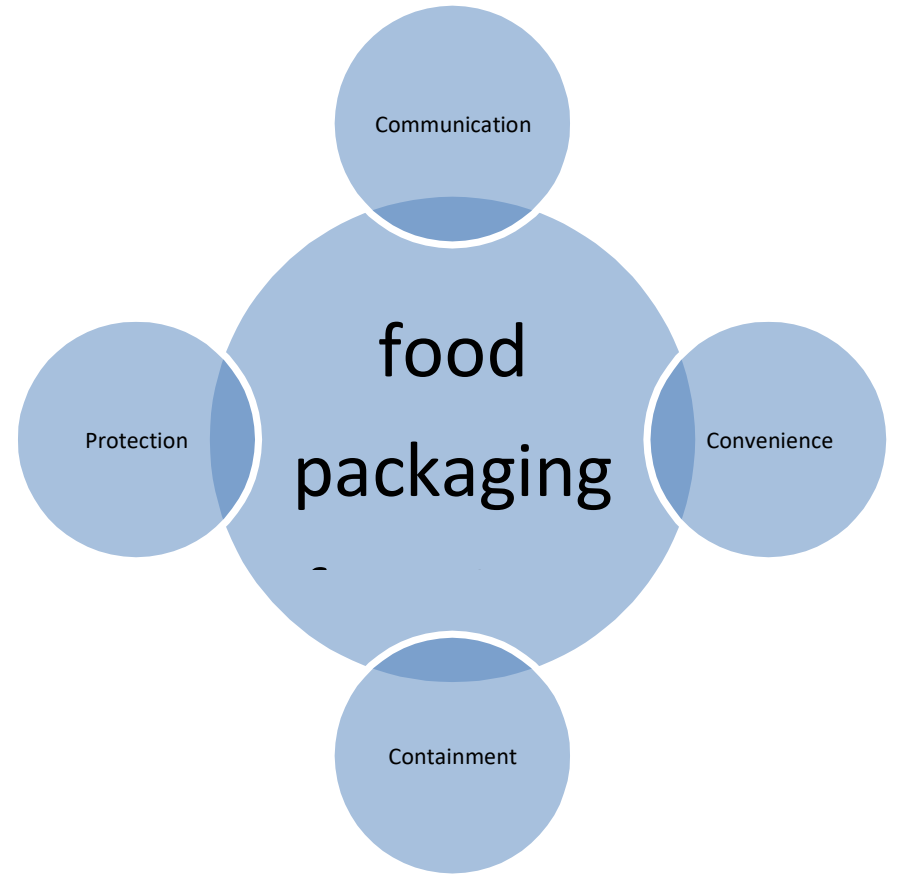

Fig. 2:- Material flow and Information flow in food supply chain cycle

\section{Application of Nanobiotechnology in Food Packaging}

\section{Nano coating}

It is one of the important concepts in which wax type coating is mostly used for apples and cheeses. Nano coating can be directly on some of the bakery products [1]. The incorporation of nanomaterials onto the packaging surface either inside or outside surface to improve the barrier properties.

\section{Oxygen scavenging materials}

Nanocomposites for food packaging. As we are familiar that $\mathrm{O}_{2}$ is responsible for deterioration of many foods either directly or indirectly. Oxygen scavenging films were successfully developed by adding Titania which is a type of nanoparticle to different polymer. Fermentation took a very important place in the concept of food packaging and its preservatives from earlier centuries. In the 19th century pioneer such as Louis Pasteur, Samuel C. Prescolt etc understood developed food packaging and preservation concepts for maintaining today's relevancy. 20th centuries invention in such as glass bottles, cellophane wrap, aluminum foil and plastics greater utility and flexibility in food packaging $[9,10]$. Microorganism causes the food spoilage, its metabolism produces gases and can be detected by conduction of polymer nanocomposites (CPC) or metal oxides. Attachment of antibodies to fluorescent, nanocomposites for detection of chemicals or pathogen born from food( food borne pathogen. To prevent spoilage and oxygen absorption, nanoclays and nanofilms are used as barrier materials. For detecting ethylene content electrochemical biosensors are used. Developments of more heat resistant films which has silicon nanoparticles and has lighter weight for the packaging of food permeation behavior of aluminum foils are modified.[11]

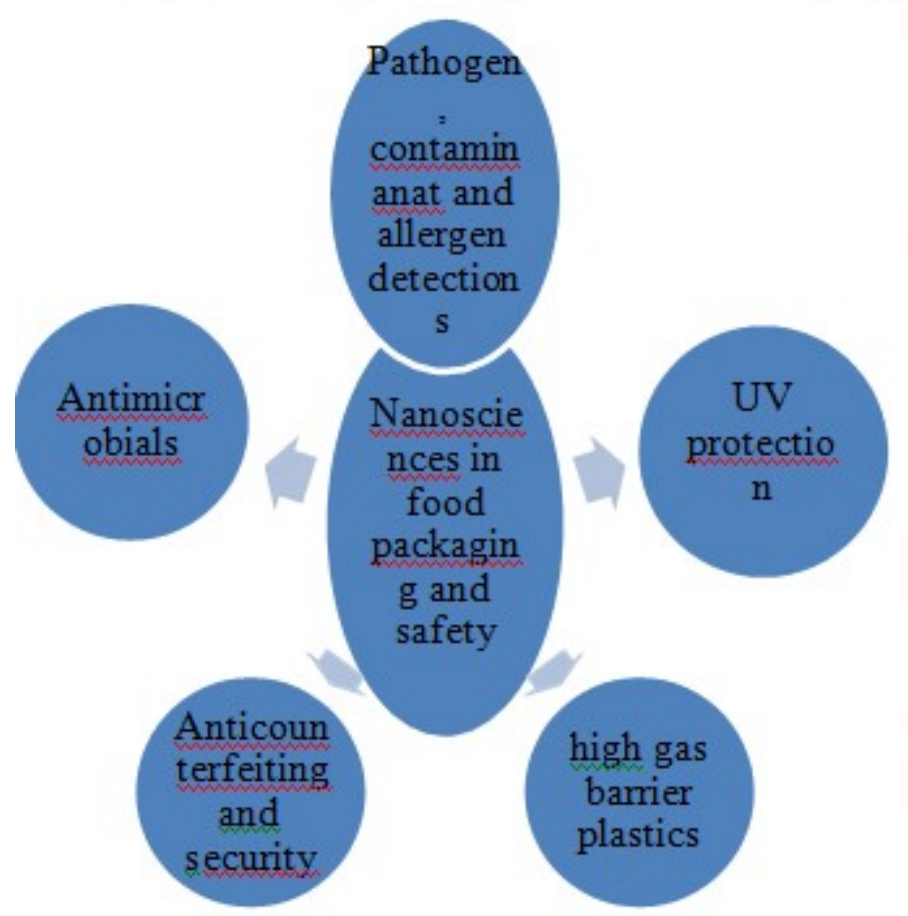

Fig. 3:- Application of nanotechnology in food packaging 
Edible nanocoating is a type of coating which can be used as meats, cheese, fruits, vegetables, confectionary, baking products and fast foods. Packaging releasing nanoscale antimicrobials, antioxidants, flavors, fragrances or nutraceuticals into food or beverages to extend its shelf life, to improve its taste and smell. Sensor packaging was also enabled by nanotechnology to incorporate cheap Radiofrequency Identification (RFID) tags. These tags are smaller flexible and printed on their labels. This helps in increasing the versatility of RFID tags and

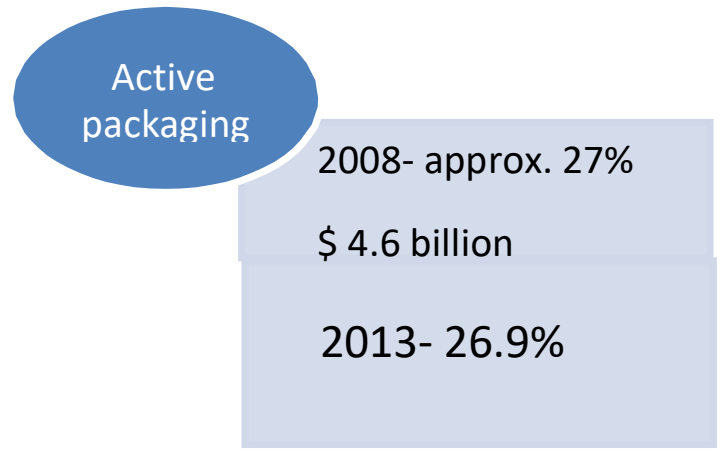

hence enabling the cheaper production $[11,13]$. Other way in the processing of nanopackaging is nonbiodegradable packaging that uses some of the nanomaterials to give strength to bioplastics (plant based plastics) is used instead of fossil fuels based plastics for the packaging of foods and carry bags.. Some of the German Research Institutes industry parties took part in forces to develop a kind of nano food packaging which should be nonstick for the products like mayonnaise and tomato sauce containers [12].

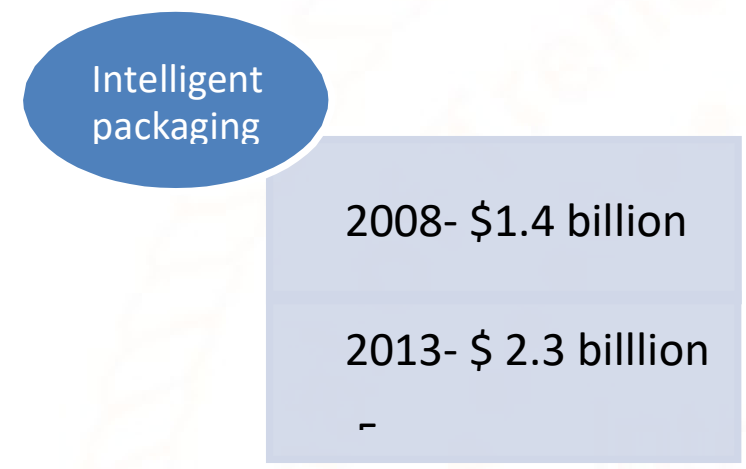

Fig. 4:- Active and Intelligent Packaging

Every product, even which are grown organically requires some sort of packaging clarity its time of protistence for protection which it is either during transportation, handling, storage or either use. Several food and beverages industries are continuously involved with new technologies which help in enhancing the product quality, its shelf life and positive impact on product profitability with the decrease in waste and spoilage of food [14]. Nanomaterials use in food packaging is truth. One of the most upcoming examples is bottles which are made up of nanocomposites which minimizes the leakage of $\mathrm{CO}_{2}$ out from bottles which increases shelf life of beverages without using heavy glass bottles or very expensive cans. Nanosensors are developed can detect bacteria and most other contaminants like Salmonella on food surface at a packaging plant (optimized web design for small business). In India, nanobiotechnology have a great potentials as innovations are getting stronger because of the young country. There is large requirement for crops, processing of food its storage as well as packaging [15].

\section{Biodegradable nanocomposites}

Certain biodegradable nanocomposites which are when synthesize as nanofibres obtains some properties which are superior.( For ex- cellulose, starch, zein \{from corn\}have increased heat resistance, they are highly thermal stable with improved barrier permeability. Food packaged in bag should be placed in box during transport [16].

\section{Nanotechnology in food safety}

Food safety in the context of nanotechnology refers that every food products must be protected from various types of contamination like physical, biological, chemical and radiation during processing, handling, as well as distribution [17]. The ingredients present in these nanoparticles must undergo the full safety assessmentA very small amount of nanomaterial given very significant opportunities for the development of pathogen- resistant surface which can be used to reduce the risk of cross- contamination of bacteria in food processing [18].

\section{Conclusion}

The branch of nanotechnology i.e nanobiotechnology has become one of the most important branches in field of food industry. In present scenario food industry shows promising results in the areas of food packaging and food safety. As to reduce the raw materials required for packaging nanomaterials are used. These nanomaterials not only helps in packaging they also protect fruits, vegetables, bakery products and confectionery from moisture and from off odours. The risk which could be caused by nanomaterial to health and environment is unknown. 
International Journal of Trend in Scientific Research and Development (IJTSRD) ISSN: 2456-6470

\section{REFERENCE}

1. Abraham, J., Colin D. Abernethy Chemistry. The Curriculum, p.169.

2. Arora, A. and Padua, G.W., 2010. Nanocomposites in food packaging. Journal of Food science, 75(1).

3. Brody, A.L., Strupinsky, E.P. and Kline, L.R., 2001. Active packaging for food applications. CRC press.

4. http://www.foodnavigator-usa.com/R-

$\mathrm{D} /$ Advances-in-nanotechnology-can-improvefoodsafety-andprep?utm_source $=$ copyright\&utm_medium $=$ OnSit e\&utm_campaign $=$ copyright

5. Kruijf, N.D., Beest, M.V., Rijk, R., SipiläinenMalm, T., Losada, P.P. and Meulenaer, B.D., 2002. Active and intelligent packaging: applications and regulatory aspects. Food Additives \& Contaminants, 19(S1), pp.144-162.

6. Majid, I., Nayik, G.A., Dar, S.M. and Nanda, V., 2016. Novel food packaging technologies: Innovations and future prospective. Journal of the Saudi Society of Agricultural Sciences.

7. Otles, S. and Yalcin, B., 2008. Intelligent food packaging. LogForum 4, 4, 3.

8. Raheem, D., 2013. Application of plastics and paper as food packaging materials-An overview. Emirates Journal of Food and Agriculture, 25(3), p.177.

9. Restuccia, D., Spizzirri, U.G., Parisi, O.I., Cirillo, G., Curcio, M., Iemma, F., Puoci, F., Vinci, G. and Picci, N., 2010

10. Scrinis, G. and Lyons, K., 2007. The emerging nano-corporate paradigm: nanotechnology and the transformation of nature, food and agri-food systems. International Journal of Sociology of Agriculture and Food, 15(2), pp.22-44.

11. Singh, T., Shukla, S., Kumar, P., Wahla, V. and Bajpai, V.K., 2017. Application of Nanotechnology in Food Science: Perception and Overview. Frontiers in Microbiology, 8, p.1501.

12. Suppakul, P., Miltz, J., Sonneveld, K. and Bigger, S.W., 2003. Active packaging technologies with an emphasis on antimicrobial packaging and its applications. Journal of food science, 68(2), pp.408-420.

13. Torney, F., Trewyn, B.G., Lin, V.S.Y. and Wang, K., 2007. Mesoporous silica nanoparticles deliver DNA and chemicals into plants. Nature nanotechnology, 2(5), pp.295-300.

14. Weiss, J., Takhistov, P. and McClements, D.J., 2006. Functional materials in food nanotechnology. Journal of food science, 71(9).

15. Wesley, S.J., Raja, P., Raj, A.A. and Tiroutchelvamae, D., 2014. Review onnanotechnology applications in food packaging and safety. International Journal of Engineering Research, 3(11), pp.645-651.

16. Wilson, C.L. ed., 2007. Intelligent and active packaging for fruits and vegetables. CRC Press.

17. Yam, K.L. and Lee, D.S. eds., 2012. Emerging food packaging technologies: Principles and practice. Elsevier.

18. Yam, K.L., Takhistov, P.T. and Miltz, J., 2005. Intelligent packaging: concepts and applications. Journal of food science, 70(1). 